\title{
Stability and numerical modelling of the "King Tiberius" cave at Riolo Terme (Ravenna-IT)
}

\author{
N. Sciarra ${ }^{1}$, M. Mangifesta ${ }^{1}$, A. Fanti ${ }^{1} \&$ R. Margutti ${ }^{2}$ \\ ${ }^{I}$ Department of Geotechnology, Chieti-Pescara University, Italy \\ ${ }^{2}$ Saint-Gobain BPB Italia S.p.A - Cinisello Balsamo, Italy
}

\begin{abstract}
This paper deals with the geo-mechanical characterization and the numerical modelling of the "King Tiberius" natural cave. The so named "Grotta di Re Tiberio", located near the gypsum quarry of "Monte Tondo", in Borgo Rivola in the village of Riolo Terme (Ravenna Province - north-east Italy) is the most famous and celebrated natural cavity of the Regional Park of the Vena del Gesso, because of archaeological evidence attesting to the presence of man over several millennia (Age of Copper). The cavity, which is due to karsts phenomena occurring in the Gypsum formation, is more than $4 \mathrm{~km}$ long and is easily explored only for a stretch of about $60 \mathrm{~m}$ up to the astonishing "Gothic Chamber". The underground mining of gypsum, which happens within the "Monte Tondo" for more than $20 \mathrm{~km}$, has caused, below the natural cavity, the collapse of a portion of pavement affected by archaeological remains. This has involved the structural analysis of the rock and the stability of the system (natural and anthropic cavities) in correspondence of the "Re Tiberius" cave. The conducted tests have involved the difficult reconstruction of the underground physical model and a numerical modelling of a significant portion of rock mass in order to propose some remedial works to safeguard and preserve the area. The modelling was implemented using a numerical code (FLAC_3D) at finite differences. The importance of the research was the analysis of the hazard relative to an interesting archaeological site in which we must operate to safeguard both the ancient human remains and the anthropic activities.
\end{abstract}

Keywords: rock stability, numerical modelling, anthropogenic activity, archaeology. 


\section{Introduction}

The "King Tiberius Cave", located near the gypsum quarry of "Round Mountain", in the village of Riolo Terme (province of Ravenna, north-east Italy; fig. 1) is the most famous and celebrated natural cavity of the Regional Park of the Vena del Gesso, because of archaeological evidence attesting to human presence over several millennia. The cavity, due to karsts in gypsum (Fig. 2a), is over $4 \mathrm{~km}$ long and is easily explored for a distance of $60 \mathrm{~m}$ to the amazing "Gothic Chamber" (fig. 2b). This stretch, in a short period, will be enhanced for tourism, with new archaeological excavations and a museum. The underground mining of gypsum, which happens in the "Round Mountain" for more than 20 $\mathrm{km}$, caused, below the natural cavities, the collapse of a portion of pavement affected by archaeological finds of the cave. This involved the study of structural influences of storage on the cave itself. The analysis conducted involved the reconstruction of the subsurface model and a numerical modelling of the entire cluster, with the presence of cavities, in order to propose some preventive consolidation precautions to safeguard and preserve the future of the cave.

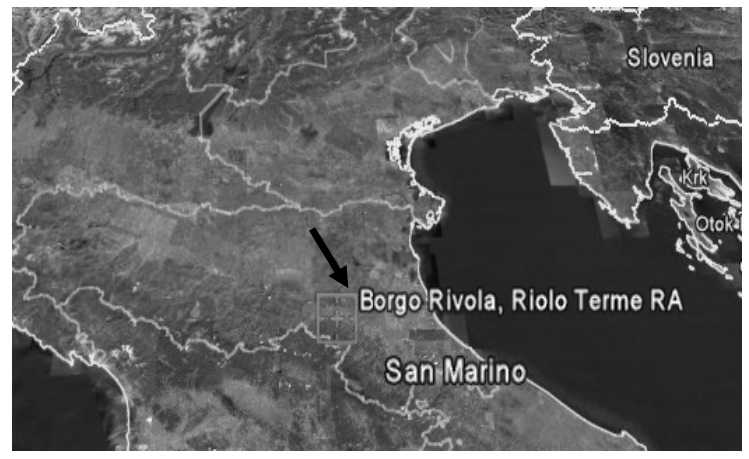

Figure 1: $\quad$ Location of the study area.
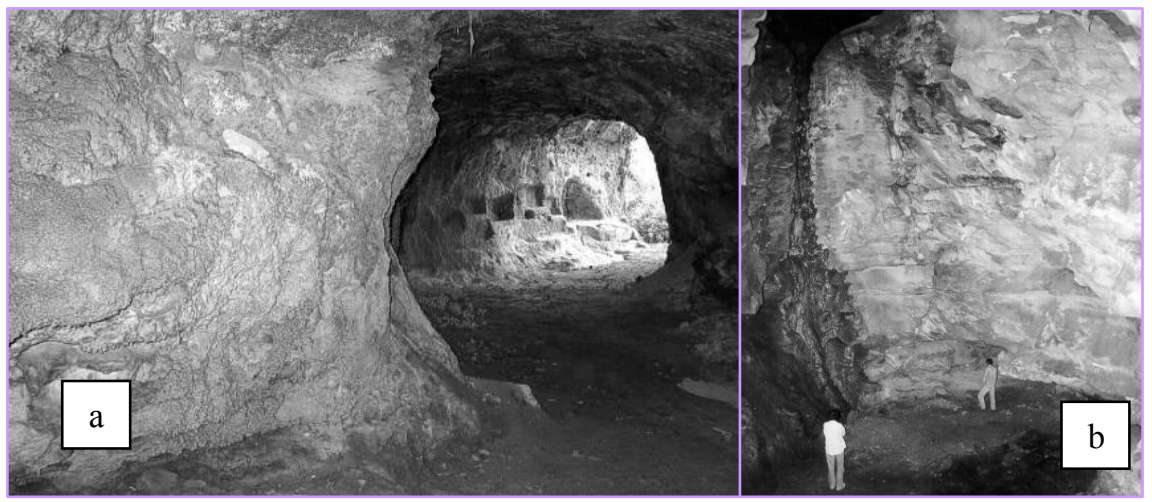

Figure 2: $\quad$ Entrance of the ancient cavity (a) and the big "Gothic Chamber" (b). 


\section{Geology}

The study area is embedded within the Park of the Vena del Gesso, which, according to the current definition, extends from the Sillaro Valley to the Lamone. The Vena del Gesso (Ricci Lucchi and Vai [1]) is characterized by the "Gessoso-Solfifera" formation that reaches a maximum thickness of $200 \mathrm{~m}$. The whole sedimentary deposit overlays the sandy or marly facies of the "MarlyArenaceous" formation. At the top, chalks are covered by the Formation of Pliocene Blue-Clay or by a few meters of chalks with flint and limestone ("Colombacci" Formation). The "Gessoso-Solfifera" formation consists of a nearly constant number of large banks with thicknesses ranging from 2 to $30 \mathrm{~m}$, fig. 3 .

In the quarry the maximum thickness of the deposit, measured through geognostic surveys, is $193 \mathrm{~m}$. The chalky outcrops have a direction of $120^{\circ}$, slope between $30^{\circ}$ and $40^{\circ}$ and dip N-NE, see fig. 3. In the northern zone, the trend of the soil layers is more inclined or coincident with the slope. The executed studies showed the presence of a faults system, the most important of which is a longitudinal fault (called the "Scarabelli" Fault) that crosses the quarry area and extends sub-parallel to the direction of gypsum banks. The existence of direct faults crossing the area of the quarry was also noted. These fault systems, which caused the intense fracturing of the chalk layers, are a privileged platform for the development of various present karsts forms (sinkholes, swallow holes and caves, fig. 4).

Some geomechanical investigations have also provided the technical parameterization of the soils, which are summarized and simplified in table 1.

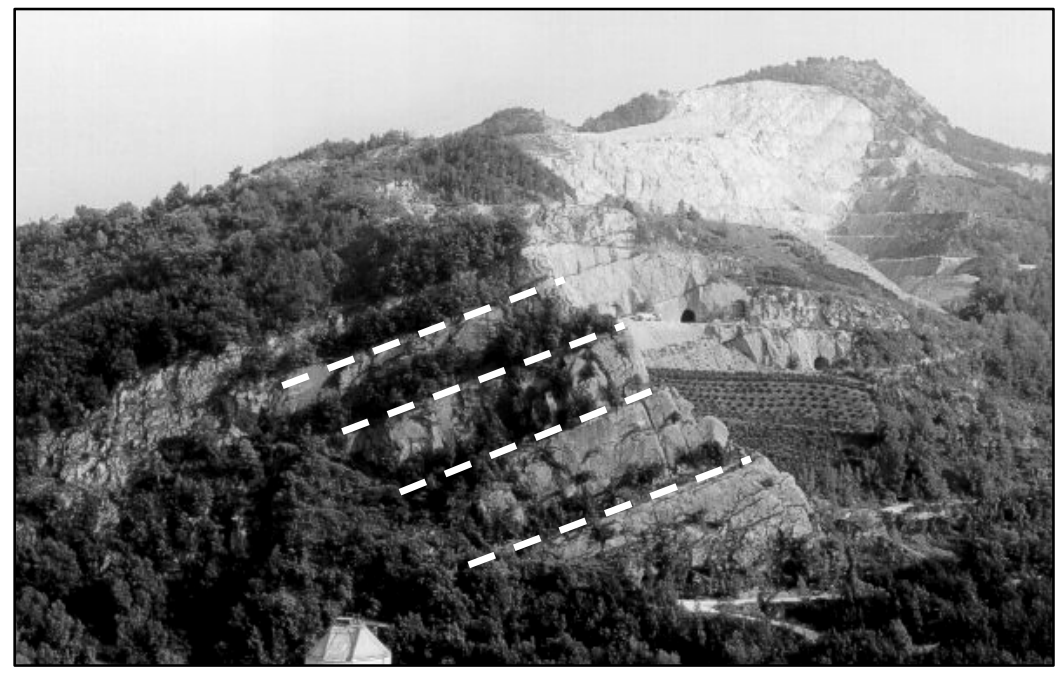

Figure 3: $\quad$ Outcrops of chalky formation with the evidence of the stratification development. 
Table 1: $\quad$ Properties of the chalky formation by laboratory and in situ tests.

\begin{tabular}{|c|c|}
\hline mass density, $\rho$ & $20 \mathrm{kN} / \mathrm{m} 3$ \\
\hline elastic bulk modulus, $K$ & $1.33 \mathrm{E} 7 \mathrm{kPa}$ \\
\hline elastic shear modulus, $\mathrm{G}$ & $7.98 \mathrm{E} 6 \mathrm{kPa}$ \\
\hline internal angle of friction of matrix, $\varphi$ & $36^{\circ}$ \\
\hline cohesion of matrix, $\mathrm{c}$ & $3.5-60 \mathrm{kPa}$ \\
\hline joint friction angle, $\varphi_{\mathrm{i}}$ & $29^{\circ}$ \\
\hline joint cohesion, $\mathrm{c}_{\mathrm{j}}=$ & $2.8-48 \mathrm{kPa}$ \\
\hline dip direction of weakness plane & $30^{\circ}$ \\
\hline dip angle of weakness plane & $35^{\circ}$ \\
\hline
\end{tabular}

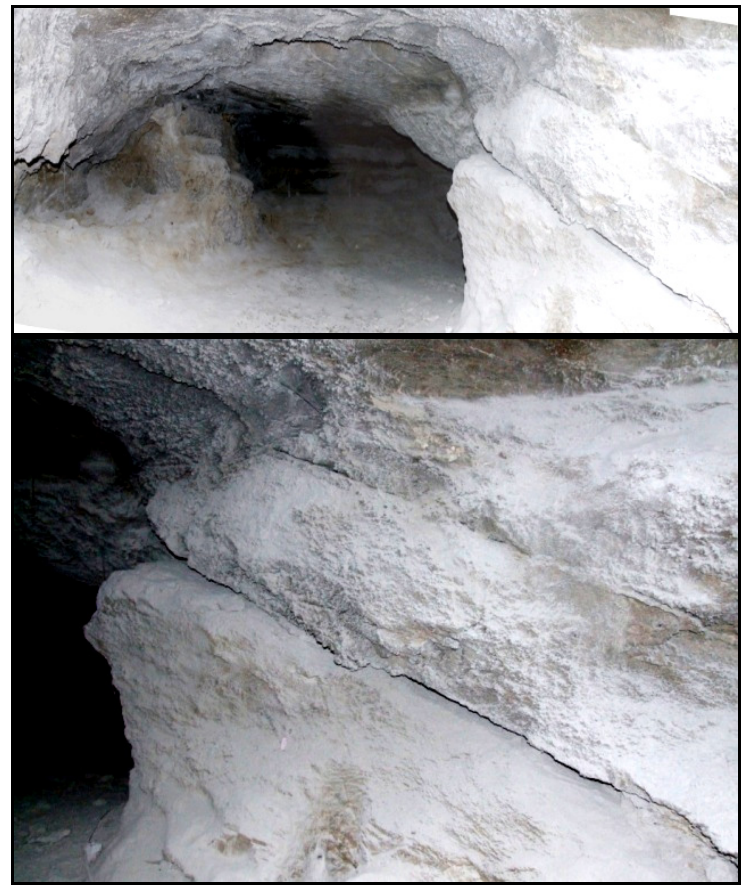

Figure 4: Various present karst forms.

\section{Geometrical reconstruction}

Considerable difficulty was found in the realization of the geometric model of the subsurface because of the complexity of simultaneously representing both the natural cavities and those that are anthropogenic. We used an accurate topographic survey that allowed us to reconstruct both the layout of the cave "King Tiberius" and the correlated section, see fig. 5. Then the GiD_8 code was used, which allows one to reconstruct the geometrical volume to the model. GiD_8 has been designed to cover all the common needs in the numerical 
simulations field from pre- to post-processing: geometrical modelling, effective definition of analysis data, transfer data to analysis software and visualization of numerical results. Thus, it was possible to include in the numerical code (FLAC_3D) the geometry of the system to be analyzed.

Some problems were encountered in the entrance area of the ancient cavity due to the interference with the topographic surface; fig. 6 shows the threedimensional particular of block 1 , which is also visible in fig. 5a, b. Because of the complexity of the model, the final geometrical discretization was divided into

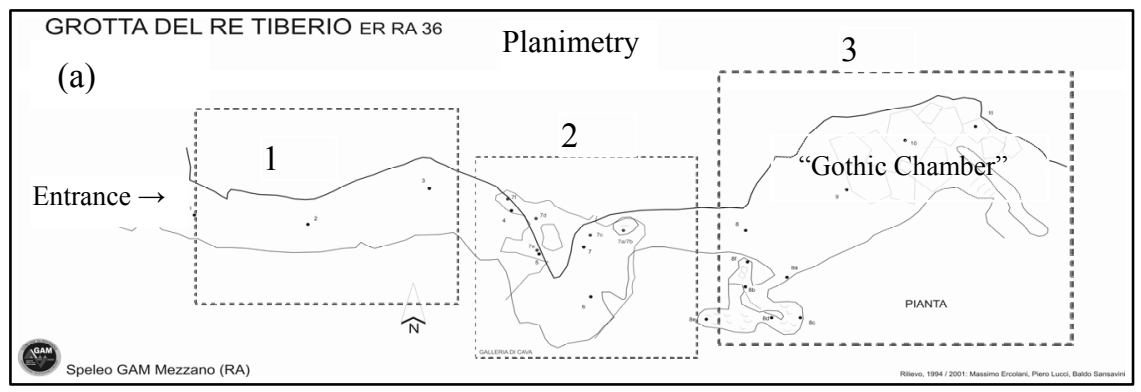

(b)
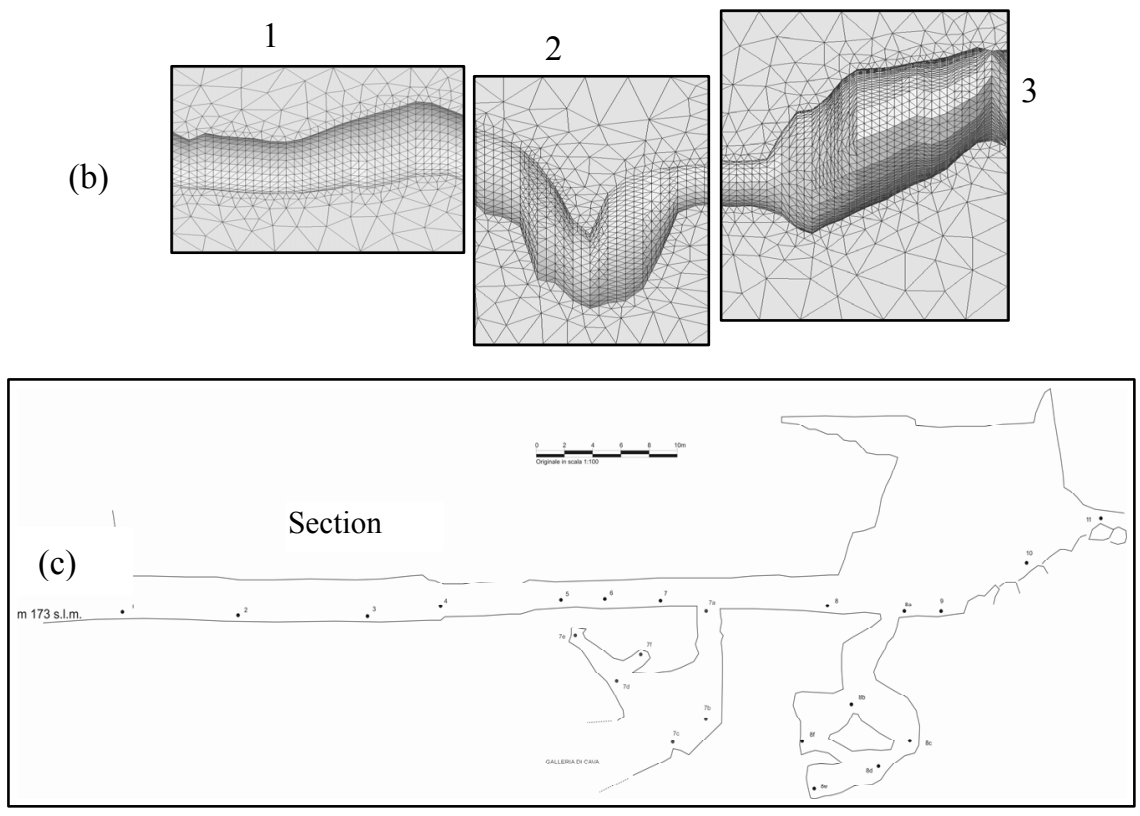

Figure 5: Planimetry (a) and section (c) of the "King Tiberius" cave; (b) shows the cave discretized for the numerical analysis. It can be noted in (a) and (b) that the rock system was divided into three blocks because of the geometrical complexity. 
three blocks for the subsequent numerical analysis. Block 2, in particular, is one where tests have been concentrated, because in this area there is interference between the ancient cave and the recent anthropogenic cavities due to the quarry, see fig. 7 .

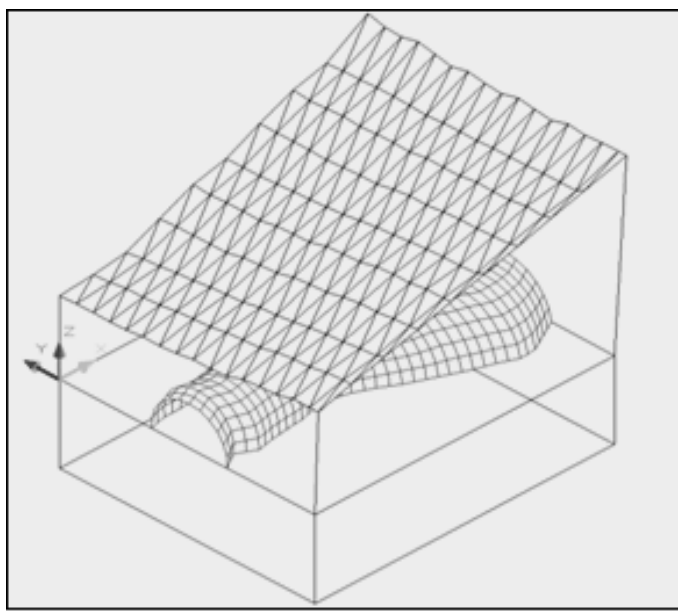

Figure 6: Detail of block 1 from Figure 5 with the introduction of the ancient cavity below the topographic surface at the entrance of the cave.
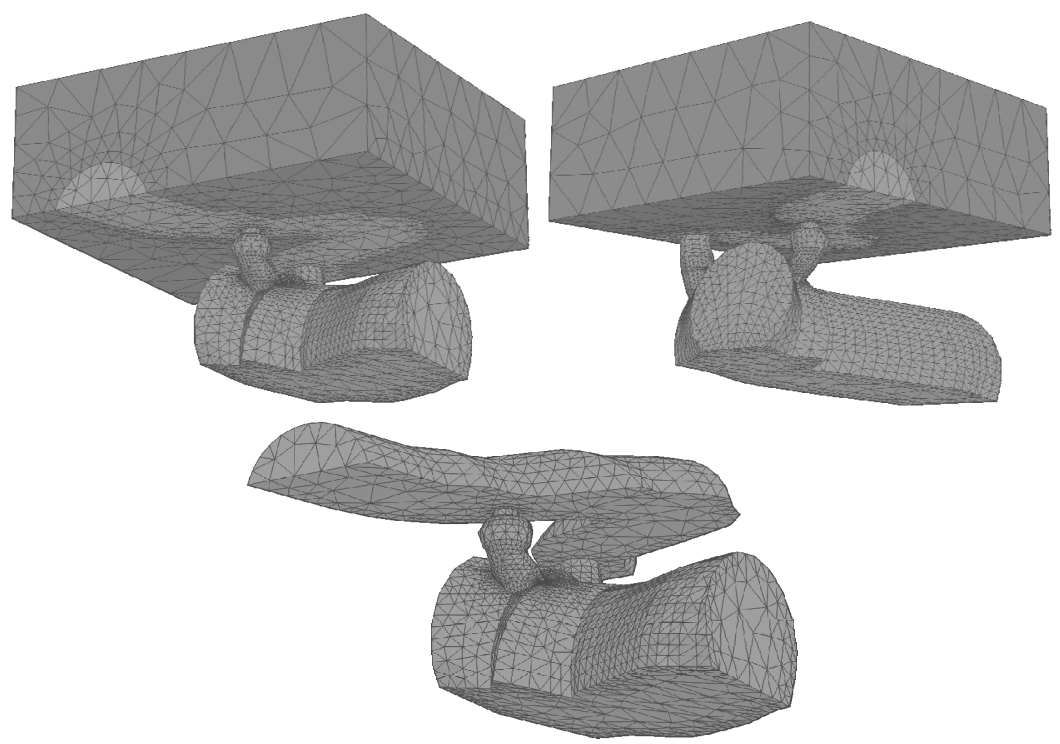

Figure 7: Detail of the geometric pattern of block 2 that shows the complexity of the development of cavities in the area of main interest (see also Figure 5). 


\section{Numerical modelling}

The numerical analyses were carried out using a finite difference calculation method with FLAC 3D (2000) code [2]. The soils were discretized into tetrahedral elements (Figure 8) and characterized by a constitutive law, such as "ubiquitous-joint", that is an extension of the Mohr-Coulomb criterion adapted for discontinuous rock systems. The general analysis carried out, as the code requires, firstly is a rebalancing of the global system and then a study of the real conditions. So we have obtained the stresses, along the walls of all cavities, that are necessary to restore the lithostatic conditions of pressures, then these had been progressively decreased to monitor the temporal evolution of the deformation state. The studies have revealed a substantial instability of the "King Tiberius" cave, unless action is taken to consolidate the mining cavity below.

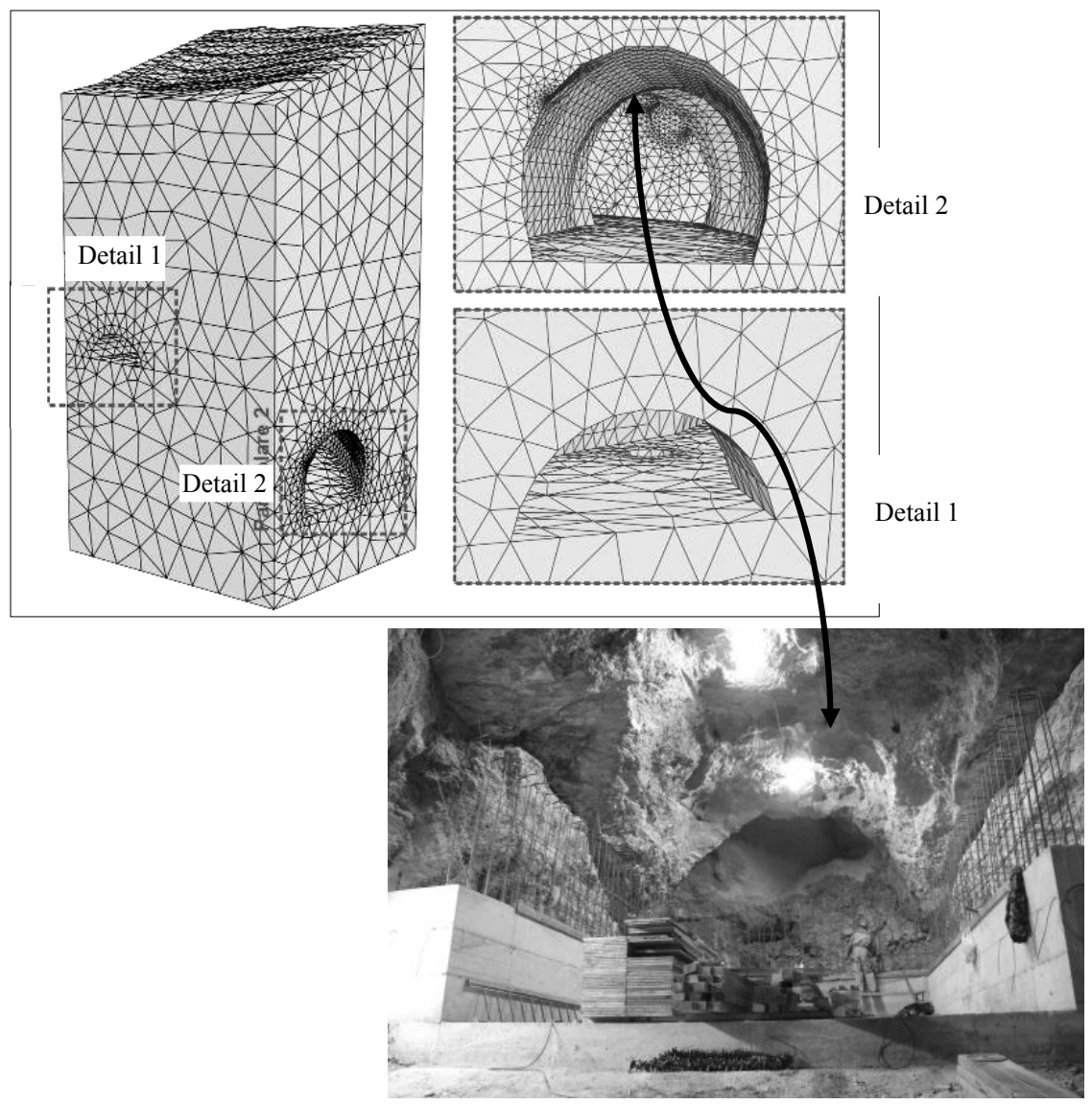

Figure 8: Details of the interferences between the "King Tiberius" Cave (upper cavity - detail 1) and the tunnel mining (lower cavity detail 2). 


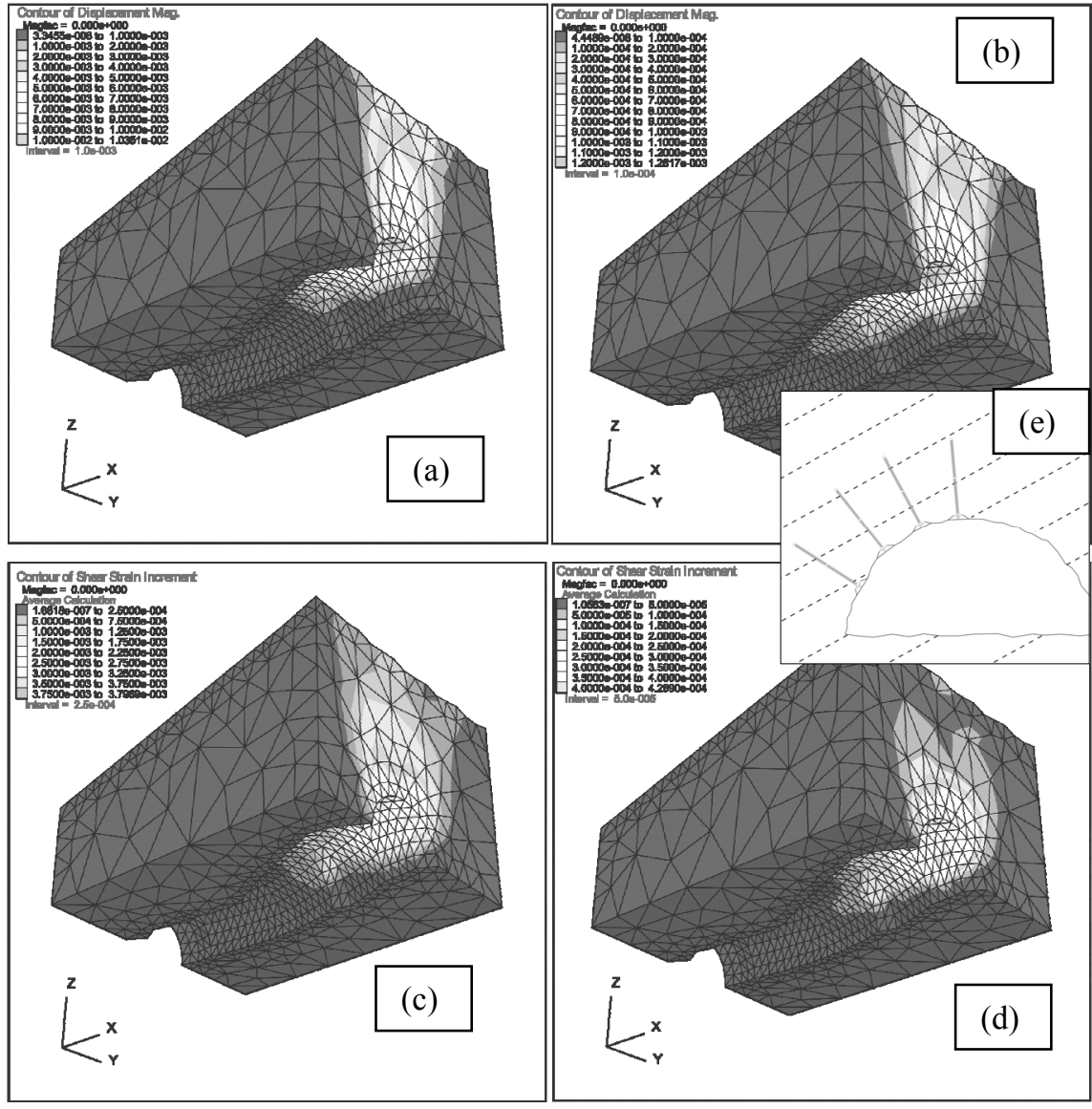

Figure 9: Test results for block 1 before and after carrying out consolidation works: displacements are shown in (a), (b) and shear deformation in (c), (d), (e) summarizes the operation performed with active riveting.

The results of numerical analyses are summarized below. We discuss only the results obtained for blocks 1 and 2 where some remedial works have been realized. Block 1 showed some problems at the vault with even centimetric displacements and important shear strain increments, see fig. 9a, c. To consolidate the vault some steel nails were designed (fig. 9e) that have undone the deformations, see fig. $9 \mathrm{~b}, \mathrm{~d}$.

Block 2 represents the zone that is particularly influenced by the anthropic mine cavities and, in fact, the modelling results demonstrated the necessity to intervene with solid structural measures. We chose the construction of a reinforced concrete structure that finally cancelled the vertical deformation of the roof of the below cavity with the consequent elimination of any deformation at the pavement of the "King Tiberius Cave", see fig. 10. 

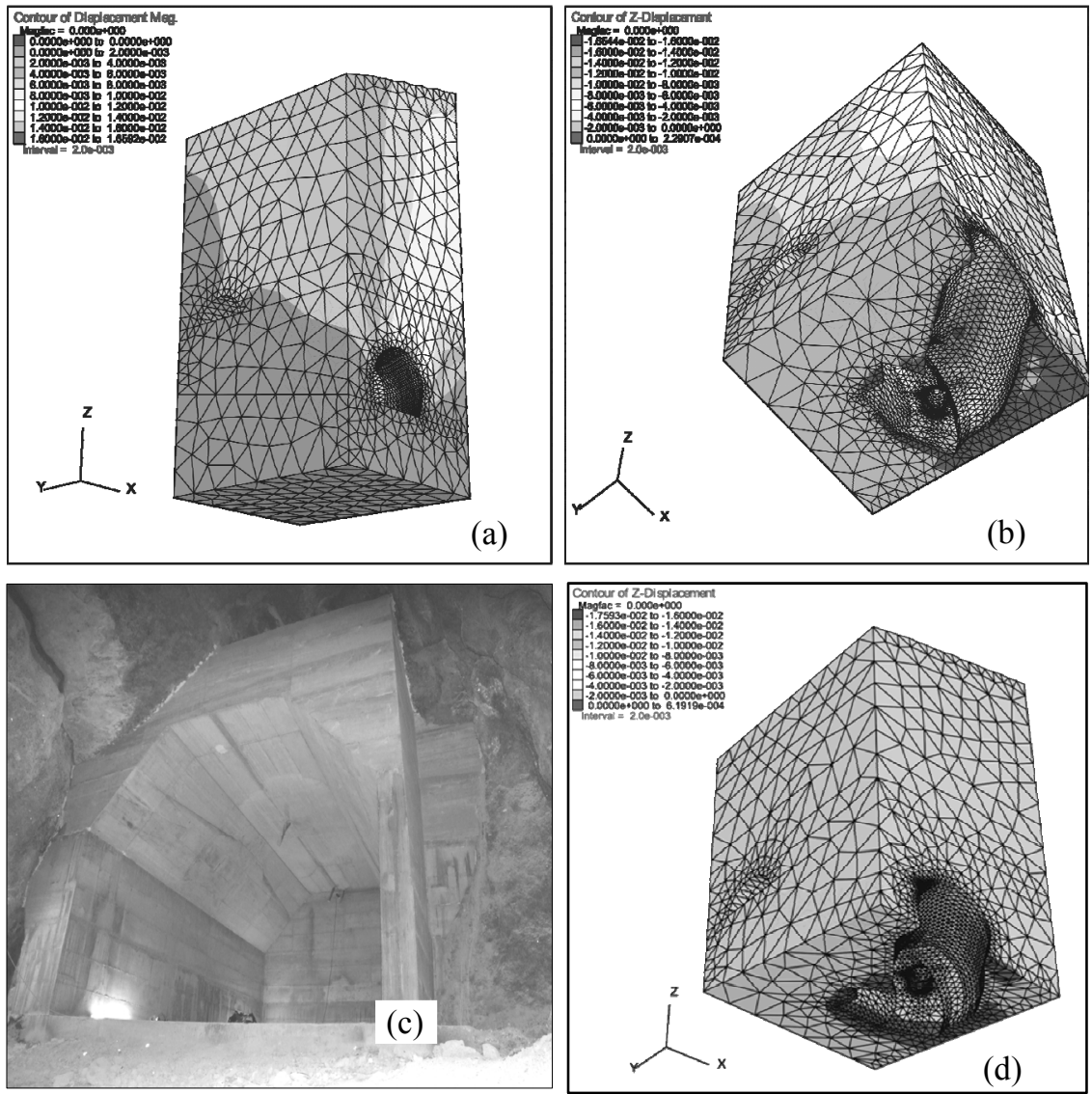

Figure 10: Analyses results for block 2 before (a, b) and after (d) carrying out consolidation works (c): vertical displacements are shown in (a), (b) and (c).

\section{Conclusions}

The present paper is the result of an accurate study for the recovery of an ancient cavity named "King Tiberius" cave, which showed some signs of instability because of a mine below it. The historical and archaeological importance of the site has involved a careful examination of the geological and geomechanical behaviour with the aim of verifying the real hazard and the most suitable systems for the mitigation of the instability causes. The remedial works have mainly involved the realization of a structure in reinforced concrete, whose successive phases of execution are visible in fig. 11, and the forecast of some steel nails applied to the vaults of the ancient cavity. Currently, thanks to the executed works, the ancient cave is viable along its entire length and it will soon be possible to use it for social and museum purposes. 


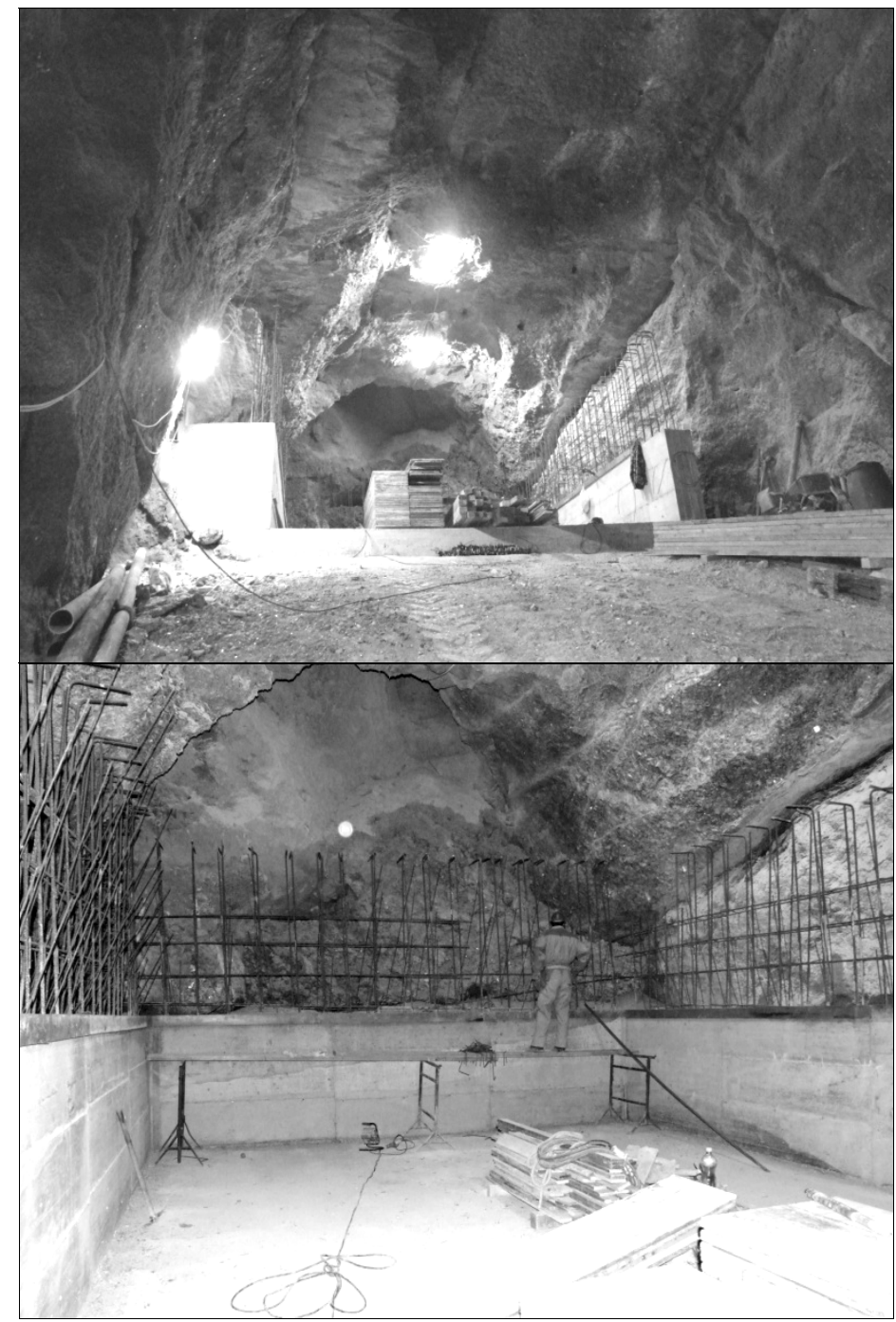

Figure 11: Successive phases of execution of the structures in reinforced concrete.

\section{References}

[1] Ricci Lucchi, E. \& Vai, G.B. La vena del Gesso. Collana Naturalistica Assessorato Programmazione e Pianificazione e Ambiente, Regione EmiliaRomagna, 1994

[2] Flac_3D. Fast Lagrangian Analysis of Continua in 3 Dimension, ver. 2.10. Itasca Consulting Group Inc., Minneapolis, USA, 2000. 